\title{
Preparation, characterization and in-vitro evaluation of sustained release protein-loaded nanoparticles based on biodegradable polymers
}

\author{
Biswajit Mukherjee \\ Kousik Santra \\ Gurudutta Pattnaik \\ Soma Ghosh \\ Department of Pharmaceutical \\ Technology, Jadavpur University, \\ Kolkata, West Bengal, India
}

Correspondence: Biswajit Mukherjee Department of Pharmaceutical Technology, Jadavpur University, Kolkata-700 032, West Bengal, India

$\mathrm{Tel}+9103324146677$

Fax+9| 03324146677

Email biswajit55@yahoo.com

\begin{abstract}
Controlled drug delivery technology of proteins/peptides from biodegradable nanoparticles has emerged as one of the eminent areas to overcome formulation associated problems of the macromolecules. The purpose of the present investigation was to develop protein-loaded nanoparticles using biodegradable polymer poly L-lactide-co-glycolidic acid (PLGA) with bovine serum albumin (BSA) as a model protein. Despite many studies available with PLGA-based protein-loaded nanoparticles, production know-how, process parameters, protein loading, duration of protein release, narrowing polydispersity of particles have not been investigated enough to scale up manufacturing of protein-loaded nanoparticles in formulations. Different process parameters such as protein/polymer ratio, homogenizing speed during emulsifications, particle surface morphology and surface charges, particle size analysis and in-vitro protein release were investigated. The in-vitro protein release study suggests that release profile of BSA from nanoparticles could be modulated by changing protein-polymer ratios and/or by varying homogenizing speed during multiple-emulsion preparation technique. The formulation prepared with protein-polymer ratio of 1:60 at 17,500 rpm gave maximum protein-loading, minimum polydispersion with maximally sustained protein release pattern, among the prepared formulations. Decreased (10,000 rpm) or enhanced (24,000 rpm) homogenizing speeds resulted in increased polydispersion with larger particles having no better protein-loading and -release profiles in the present study.
\end{abstract}

Keywords: bovine serum albumin (BSA), poly-L-lactide-co-glycolidic acid (PLGA), nanoparticles

\section{Introduction}

Increasing numbers of therapeutic agents emerging from rapid growth of biotechnological research components of pharmaceutical drug discovery are macromolecules such as proteins (Hermes and Narayani 2002; Muller and Keck 2004; Kavimandan et al 2006). The advances in recombinant DNA technology have ensured the easy and abundant availability of several genetically engineered regulatory and therapeutic proteins such as hormones, growth factors, vaccines, immunosuppressors and so on. However, various difficulties are encountered in formulating proteins/peptides for therapeutic uses (Hermes and Narayani 2002; Wei-Chiang 2003). Proteins cannot be readily delivered orally or through skin due to rapid degradation by proteolytic enzymes in the gastrointestinal tract and poor pass through the biological barrier, respectively. Due to short biological half-lives, repeated injections are generally needed and it is painful. Another serious problem in delivering proteins is their inherent physical and chemical instability. However, a possible solution to improve biological half-lives is the controlled delivery of proteins from biocompatible polymers. While various routes such as ocular, transdermal, 
nasal and buccal have been tried (Banga and Chien 1988; Shoyele and Slowey 2006), none of these routes has proved to be a potential alternative to the invasive injection. New and/or improved methods of administration are being constantly tried. Nanoparticles are the nanosize particulate dosage forms that are being extensively tried to deliver proteins as they can protect the protein from metabolizing enzymes and can sustain the release and target specific tissues by incorporating surface ligand moieties (Muller and Keck 2004). PLGA is a well-characterized biodegradable polymer approved for human use by US Food and Drug Administration (US FDA) (Chun and Phuong-Truc 2008). PLGA has different varieties with different characteristics. Many studies (Lamprecht et al 1999; Qaddoumi et al 2004; Bilati et al 2005; Lee et al 2007) are available on PLGA (50:50)-based nanoparticles, however, few studies (Zhu and Schwendeman 1999) have been reported with PLGA $(85: 15)$, the variety chosen in the present study. PLGA $(85: 15)$ has a molar ratio of L-lactide and glycolide, 85/15. Advantage of the lactide and glycolide copolymers is the well documented versatility in polymer properties and performance characteristics (Chohen et al 1991; Berkland et al 2001). Bovine serum albumin (BSA) was used as model protein since it is one of the most stable and widely-used proteins for evaluating novel sustained release drug delivery system (Ravi Kumar 2000). Great amount of research in the field of biodegradable microparticles and some research related to biodegradable nanoparticles, containing peptide or protein drugs have been available in the literatures (Panyam and Labhasetwar 2003; Mohanraj and Chen Y 2006). However, production know-how, effects of critical parameters influencing successful protein-loading, desired protein release pattern, prolonging duration of release, stability of proteins in formulation, narrowing polydispersity of nanoparticles etc. have not been investigated enough to formulate them commercially. Rather many more studies are required to scale up them as formulations for industrial production. Under these circumstances, if we can add even a little finding to the existing scientific information, this could be valuable in real term in the development of nanoparticles, in particular and nanoscience as a whole.

The purpose of the present investigation was to develop protein (BSA)-loaded nanoparticles with biodegradable polymer, poly L-lactide-co-glycolidic acid (PLGA), using multiple emulsification (water-in-oil-in-water, w/o/w) and solvent evaporation technique and standardization of various process parameters such as protein/polymer ratio, homogenizing speed during emulsifications, particle surface morphology and surface charges, particle size analysis and in-vitro protein release to obtain nanoparticles with maximum protein-loading, minimum polydispersion with a maximally sustained protein release pattern, among the prepared formulations.

\section{Experiment}

\section{Materials}

Bovine serum albumin (BSA) and poly L-lactide-co-glycolidic acid (85:15), PLGA, were procured from Sigma-Aldrich Chemicals Pvt. Ltd., Bangalore, Karnataka, India. Polyvinyl alcohol (PVA, M.W. 30,000-70,000) was obtained from S.d Fine Chem. Ltd., Mumbai, Maharastra, India. Dichloromethane (DCM) was purchased from E.Merck Ltd., Mumbai, Maharastra, India. All other chemicals used were of analytical grade.

\section{Methods}

\section{Method of preparation of nanoparticles}

Required amount of PLGA (Table 1) was taken in a beaker and dissolved in DCM. Then a specified amount of it was added to $2.5 \%$ of PVA containing BSA and was homogenized for $4 \mathrm{~min}$ at specified rpm. The above mixture was added dropwise to $75 \mathrm{~mL}$ of $1.5 \%$ PVA in a $400 \mathrm{~mL}$ capacity glass beaker and homogenized for $6 \mathrm{~min}$ at specified rpm (Table 1) to produce $\mathrm{w} / \mathrm{o} / \mathrm{w}$ emulsion. The emulsion was then stirred on a magnetic stirrer overnight to evaporate DCM. The nanoparticles were then washed thrice using double distilled water by centrifugation at 16,000 rpm for $40 \mathrm{~min}$. Samples were frozen for $3 \mathrm{~h}$ at $-20{ }^{\circ} \mathrm{C}$ and freeze-dried for $48 \mathrm{~h}$ in $10 \mathrm{~mL}$ freeze drying vial (initial self-temperature was $-15^{\circ} \mathrm{C}$ and it was reduced to $-40{ }^{\circ} \mathrm{C}$ and kept for 48 hours). Self-temperature was then elevated to $15^{\circ} \mathrm{C}$ and removed.

\section{Characterization of protein-loaded nanoparticles}

\section{Study of protein excipients interaction through} fourier transform infra-red spectroscopy

The pure protein, mixture of protein with PLGA and PVA and mixture of PLGA and PVA were mixed separately

Table I Batch specification

\begin{tabular}{lll}
\hline $\begin{array}{l}\text { Formulation } \\
\text { code }\end{array}$ & $\begin{array}{l}\text { BSA: PLGA } \\
\text { ratio }\end{array}$ & $\begin{array}{l}\text { Speed of homogenization } \\
(\mathbf{r p m})\end{array}$ \\
\hline GI & $\mathrm{I}: 50$ & 10,000 \\
G2 & $\mathrm{I}: 50$ & 12,500 \\
G3 & $\mathrm{I}: 50$ & 15,000 \\
G4 & $\mathrm{I}: 60$ & 17,500 \\
\hline
\end{tabular}


with IR grade $\mathrm{KBr}$ in the ratio $1: 100$ and corresponding pellets were prepared by applying 5.5 metric ton of pressure in a hydraulic press. The pellets were scanned over a wave number range of 4000 to $400 \mathrm{~cm}^{-1}$ in Magna IR 750 Series II (Nicolet, Madison, WI, USA) fourier transform infra-red (FTIR) instrument.

\section{Determination of polydispersibility}

Polydispersibility was performed by the instrument Zetasizer nano ZS with DTS software (Malvern Instrument Limited, UK). NIBS ${ }^{\circledR}$ (noninvasive backscatter optics) technology was used for measurements of particles. The formulations were taken in lyophilized form in microcentrifuge tubes, suspended in phosphate buffer, $\mathrm{pH} 7.4$ and introduced in the instrument to read the results.

\section{Determination of zeta potential}

Zeta potential of different formulations was measured by the instrument zetasizer nano ZS using DTS software (Malvern Instrument Limited, UK) using M3-PALS technology. The experimental formulations were taken in lyophilized form in $2 \mathrm{~mL}$ eppendrof tube and the samples were suspended in phosphate buffer, $\mathrm{pH} 7.4$ and then introduced in the instrument following the guideline of the manufacturer. The results were then read.

\section{Study of morphology of nanoparticles by scanning electron microscopy}

Surface morphology was determined by scanning electron microscopy (JEOL, JSM5200, TOKYO, Japan). The samples were spread on metal stubs and gold coating was done by using an ion-sputtering device. The gold-coated samples were vacuum dried and then examined.

\section{Protein-loading study}

A known amount of protein-loaded nanoparticles were added to a solution of 5\% SLS-NaOH. After a definite period of time, the dispersed phase was separated from the continuous phase by means of centrifugation. Then the supernatant was collected and released protein was assayed spectrophotometrically using Bio-Rad Protein Assay Kit.

\section{Release study}

Protein-loaded formulations $(5 \mathrm{mg}$ ) were weighed and suspended in $1 \mathrm{~mL}$ phosphate buffered saline in $2 \mathrm{~mL}$ eppendrof tubes. They were then incubated at $37^{\circ} \mathrm{C}$ with constant shaking. The samples were kept for specified periods of time $(2,5,10,15,20$, and up to 50 days, respectively) and were analyzed for protein determination.

\section{Results}

Drug-excipient interaction study is an important study to formulate a chemical entity with the other chemicals in a sustained release delivery system, so that the desire release pattern and other requisite physico-chemical characteristics may be achieved (Mukherjee et al 2005a). Among the various methods available, FTIR spectroscopy provides us a distinct idea regarding interaction between various functional groups present in drug and excipients (Cunha-Filho et al 2007). In the present study when the FTIR spectrum of BSA, PLGA-PVA and BSA with PLGA-PVA (Figures 1, 2, and 3) were compared, no physico-chemical interaction was detected. Hence, the polymer was used to formulate the protein.

The results of particle size analysis by laser diffraction showed that particle sizes varied from $<50 \mathrm{~nm}$ to $985 \mathrm{~nm}$ with variable polydispersity indices among the experimental formulations (Table 2). About more than 70\% particles found to have diameter below $700 \mathrm{~nm}$. However, the densest and narrowest range of particle dispersion was noticed between $300 \mathrm{~nm}$ and $600 \mathrm{~nm}$ in case of formulation G4 (Figure 4), among the prepared formulations.

Table 2 depicts the various process parameters of the prepared protein containing nanoparticles. Formulation G4 had the least value of the average diameter, whereas G1 had the maximum. The polydispersibility indices also showed the similar patterns of dispersibilities ie, formulation G4 had the least value and G1 had the maximum. All the formulations had negative zeta potential values varied between -3.85 to $-4.81 \mathrm{mV}$. G4 had the value of $-4.30 \mathrm{mV}$ whereas $\mathrm{G} 1$ had $-3.85 \mathrm{mV}$. When mobility was compared G4 had a lower mobility value of -0.2260 as compared to that of G1, which was -0.3022 . Conductivity was found to be the highest $(21.23 \mathrm{~ms} / \mathrm{cm})$ in G4 among all the experimental formulations and the least value was seen in G1, which was $10.37 \mathrm{~ms} / \mathrm{cm}$.

SEM photograph (Figure 5) shows that the prepared particles were spherical in shape and a major portion of the particle distribution was occupied by very small particles in nano range size as compared to the larger particles which were also below $1 \mu \mathrm{m}$ in size. This was further confirmed by particle size analysis, which showed that size distribution varied from $<50 \mathrm{~nm}$ to $985 \mathrm{~nm}$ range. There was a clear distribution of both the small and large particles and they were not conglomerated. Again the denser particle 


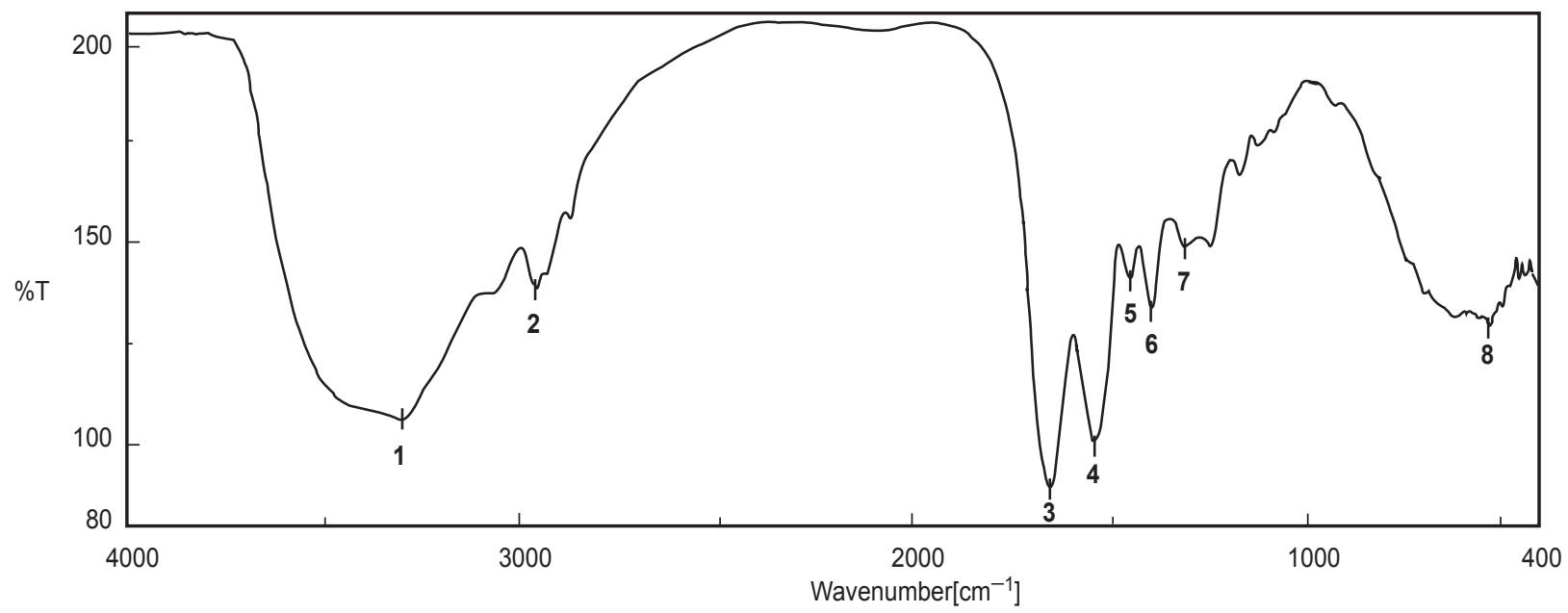

\begin{tabular}{|c|c|c|c|}
\hline Accumulation & 42 & Resolution & $4 \mathrm{~cm}^{-1}$ \\
\hline Zero Filling & ON & Apodization & Cosine \\
\hline Gain & 4 & Scanning Speed & $2 \mathrm{~mm} / \mathrm{sec}$ \\
\hline Date/Time & 10/17/06 3:33PM & & \\
\hline Update & 10/17/06 3:35PM & & \\
\hline Operator & SATYA & & \\
\hline File Name & Memory\#5 & & \\
\hline Sample Name & $D-1$ & & \\
\hline Comment & $\mathrm{KBr}$ & & \\
\hline
\end{tabular}

1:3301.54,106.028 2:2960.2, 138.102 3:1655.59, 88.0355 4:1543.74, 98.586

5:1450.21,139.644 6:1398.14, $131.871 \quad 7: 1309.43,147.348$ 8:529.364, 127.413

Figure I FTIR spectra of BSA.

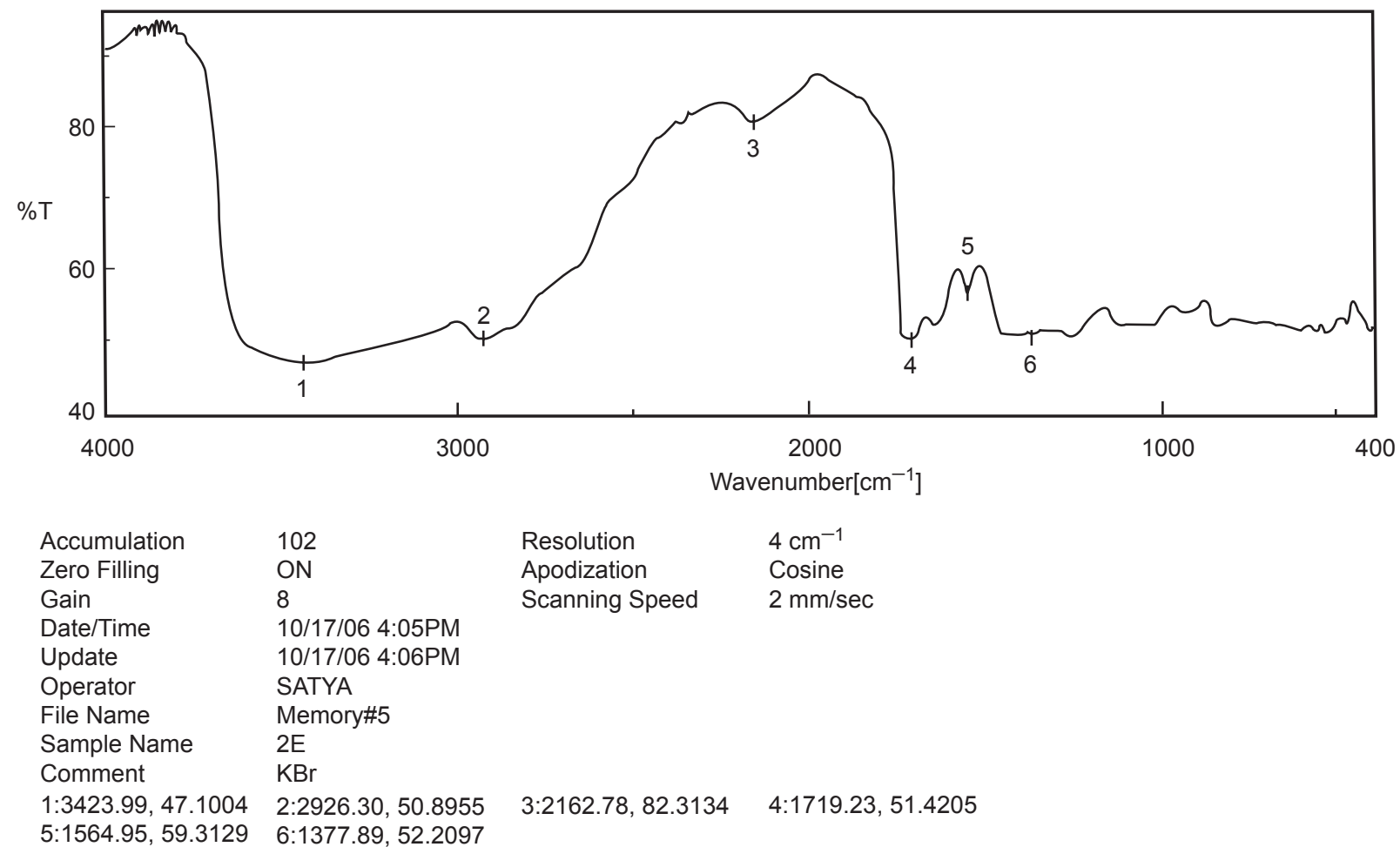

Figure 2 FTIR spectra of excipients. 


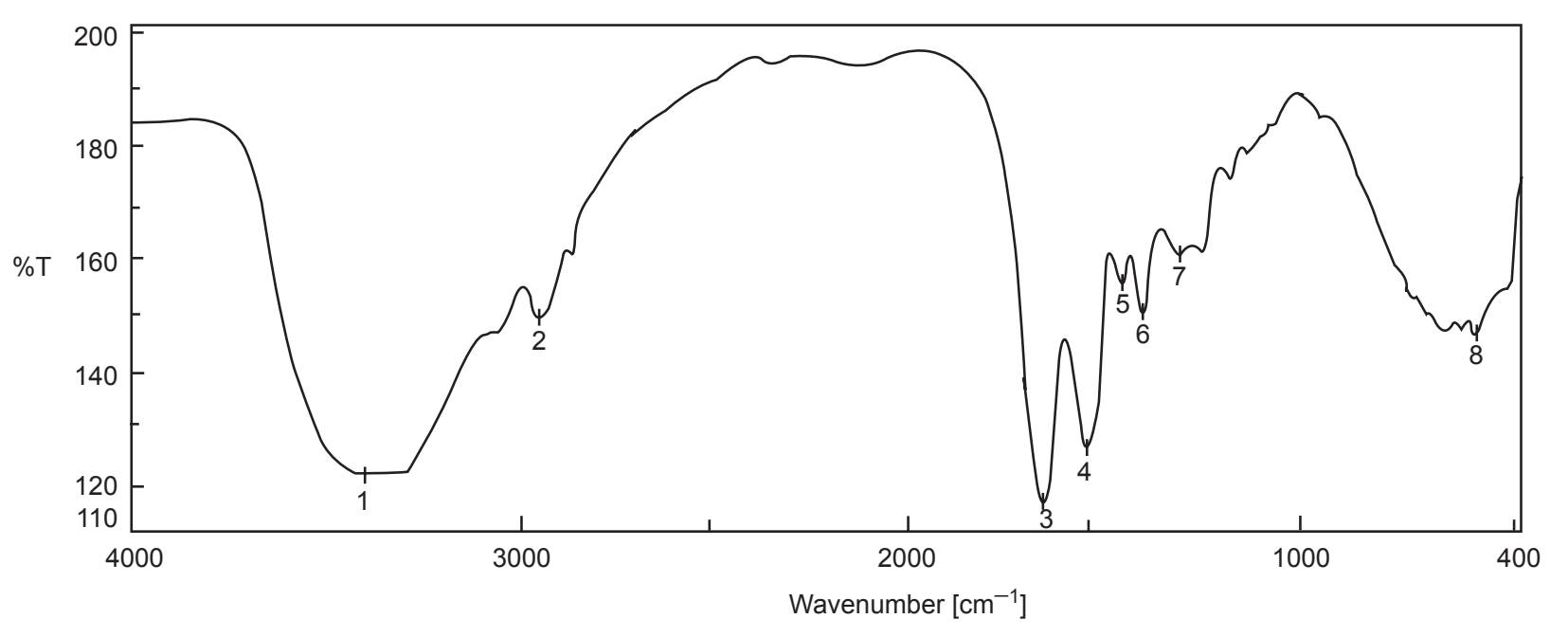

\begin{tabular}{|c|c|c|c|}
\hline Accumulation & 43 & Resolution & $4 \mathrm{~cm}^{-1}$ \\
\hline Zero Filling & ON & Apodization & Cosine \\
\hline Gain & 410/17/06 3:51PM & Scanning Speed & $2 \mathrm{~mm} / \mathrm{sec}$ \\
\hline Date/Time & 10/17/06 3:53PM & & \\
\hline Update & SATYA & & \\
\hline Operator & Memory\#5 & & \\
\hline File Name & $\mathrm{D} 3+\mathrm{E}$ & & \\
\hline Sample Name & $\mathrm{KBr}$ & & \\
\hline Comment & & & \\
\hline $1: 3412.42,120.408$ & $2: 2960.2,145.636$ & $3: 1655.59,112.388$ & $4: 1543.74,121.815$ \\
\hline $5: 1450.21,152.221$ & $6: 1398.14,145.896$ & $7: 1308.46,155.6$ & $8: 528.4,141.058$ \\
\hline
\end{tabular}

Figure 3 FTIR spectra of BSA and excipients.

distribution was seen between $300 \mathrm{~nm}$ and $600 \mathrm{~nm}$, with an average particle size $497 \mathrm{~nm}$.

The average $(n=6)$ protein loading in $\mathrm{G} 4$ formulations was found to be $38.6 \% \mathrm{w} / \mathrm{w}$ of the formulations.

Protein release study was carried out to understand the protein release pattern from the formulations. After 10 days release of the protein was about $30 \%$ of the protein content.

When protein release study was conducted it was found that the cumulative amount of the protein release in 50 days was $83.52 \mu \mathrm{g}$ per $\mathrm{mg}$ of formulation in case of G1. The values were $82.31,72.35,60.75 \mu \mathrm{g}$ per $\mathrm{mg}$ of formulation in case of G2, G3 and G4, respectively (Figure 6). When the cumulative percentages of the protein release from the experimental formulations were plotted against time, it was found that about $84 \%$ protein was released in 50 days in case of the formulation G3, whereas, G4 had a release of about $42 \%$ in the same time period (Figure 7). G1 and G2 had a cumulative percentage release of about $61 \%$ and $77 \%$, respectively.

From the release kinetics it was evident that formulation G1, G2 and G3 followed zero order kinetics, whereas, G4 was closest to apparent zero order kinetic (Table 3).

\section{Discussion}

In the present study, PLGA was selected to formulate BSA-loaded nanoparticles. Initially drug-excipient

Table 2 Characterization of protein-loaded nanoparticles

\begin{tabular}{lllllll}
\hline $\begin{array}{l}\text { Formulation } \\
\text { code }\end{array}$ & aZ-Ave (nm) & Polydispersibility & $\begin{array}{l}\text { Zeta potential } \\
(\mathbf{m V})\end{array}$ & Mobility & $\begin{array}{l}\text { Conductivity } \\
(\mathbf{m s} / \mathbf{c m})\end{array}$ & $\begin{array}{l}\text { Loading capacity } \\
(\%) \pm \mathbf{S D}(\mathbf{n}=\mathbf{6})\end{array}$ \\
\hline GI & 918 & 0.050 & -3.855 & -0.3022 & 10.37 & $25.19 \pm 0.085$ \\
G2 & 795 & 0.032 & -4.674 & -0.3664 & 11.53 & $28.17 \pm 0.014$ \\
G3 & 612 & 0.016 & -4.816 & -0.3776 & 18.98 & $31.19 \pm 0.083$ \\
G4 & 497 & 0.013 & -4.300 & -0.2260 & 21.23 & $38.29 \pm 0.085$ \\
\hline
\end{tabular}

Note: ${ }^{\mathrm{ZZ}-A v e}$ represents average particle size diameter. 


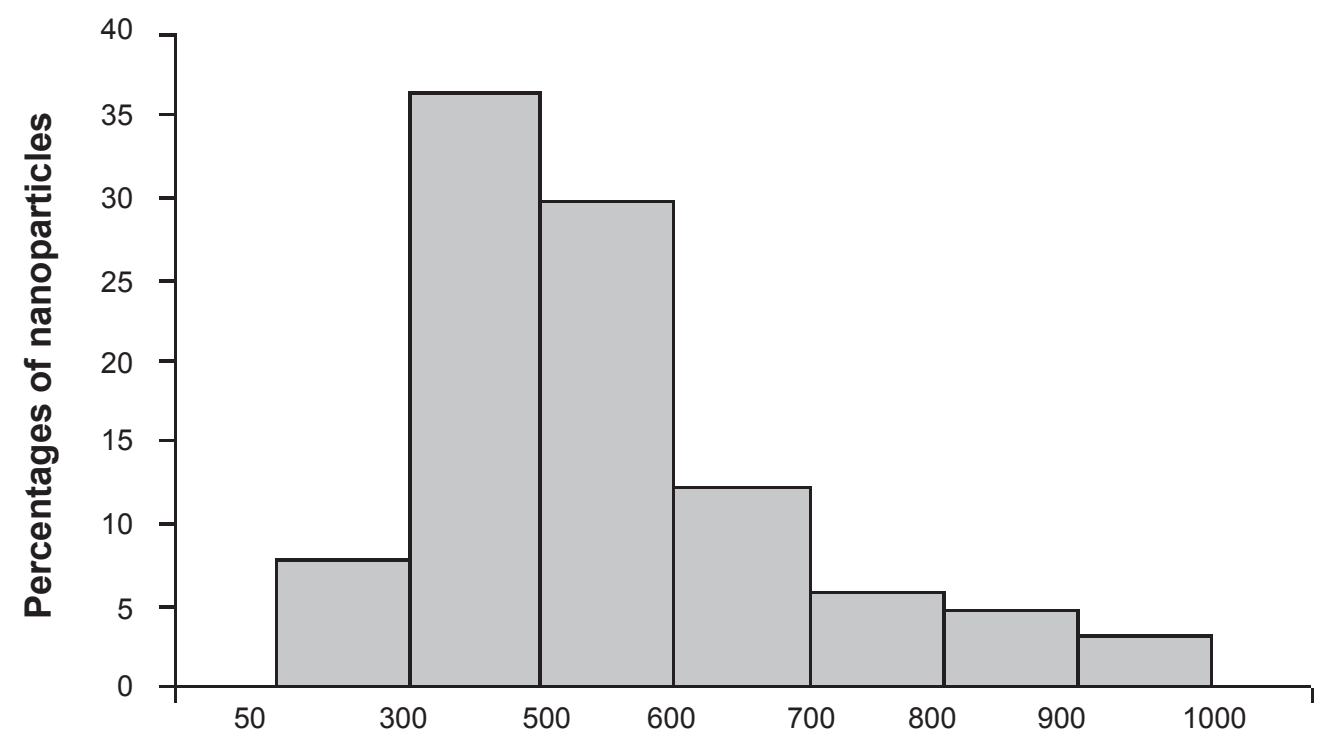

Nanometer ranges

Figure 4 Polydispersity pattern of G4.

interaction study was conducted since it is an important study to determine if there is any interaction between the drug and the excipients (Ya-Ping 2001). Drug-excipient interaction predicts the characteristics of drug release from a formulation (Mukherjee et al 2005b). The level of interaction between BSA and PLGA at the level of functional groups through FTIR spectroscopy has not been reported so far in the literature. In the present experiment, the BSA-excipient interaction study was conducted with the help of FTIR spectroscopy, which is one of the latest and very powerful techniques that can indicate drug-excipient interactions among the various functional groups between the drug (protein) and the excipient molecules (Maghraby and Ali 2007). Our data reveal that no predominant interaction existed between the protein and the excipients. Hence, PLGA and PVA were selected to formulate BSA.

Polydispersity varies from formulations to formulations. Reports have shown that the polydispersity variation existed from $100 \mathrm{~nm}$ to even $20 \mu \mathrm{m}$ (Panyam et al 2003; Qaddoumi et al 2004; Han et al 2005). Variation in a range of few hundred nm is also very common (Song et al 1997). However, the denser mode of particle sizes in polydispersity range is important to compare polydispersity data with the other findings and in our study this has existed between $300 \mathrm{~nm}$ and $600 \mathrm{~nm}$ with about $70 \%$ particles below $700 \mathrm{~nm}$ size. Thus the finding is very encouraging in terms of less polydispersity of particle size in real terms.
Zeta potentials reported for PLGA based nanoparticles were found to vary from $-3.54 \mathrm{mV}$ to $-4.04 \mathrm{mV}$ (G'omez-Gaete et al 2007). The findings of zeta potential study are given in Table 2 . In the present study this value is within the range. Particles with zeta potentials more positive than $+30 \mathrm{mV}$ and more negative than $-30 \mathrm{mV}$ are normally considered stable for colloidal dispersion (Yue et al 2008). From the data it is evident that all the formulations are unstable in the colloidal state. This suggests that the particles should not be stored in a liquid suspension form and rather they should be stored in a lyophilized state. Immediately before the administration they should be reconstituted. Reports suggest that formulations stored in colloidal stage cause more stability problem than in the dry form (Abdelwahed et al 2006).

Poly (ethylene glycol)-poly (L-histidine)-diblock copolymer is an effective excipient preserving stability of BSA-PLGA microspheres in aqueous solution (Kim et al 2005). PLGA degrades through acid catalyzed hydrolysis and produces carboxylic acids. Neutralizing the acidic microenvironment with the degraded PLGA microsphere system caused an improved release kinetics and stability of the encapsulated protein. Poly(ethylene glycol)poly(L-histidine)-diblock copolymer forms an ionic complex with a negatively charged BSA with a pH range 4.9-6.5 and being a weekly basic component it can neutralize acidic microenvironment of PLGA created by acid degradation 


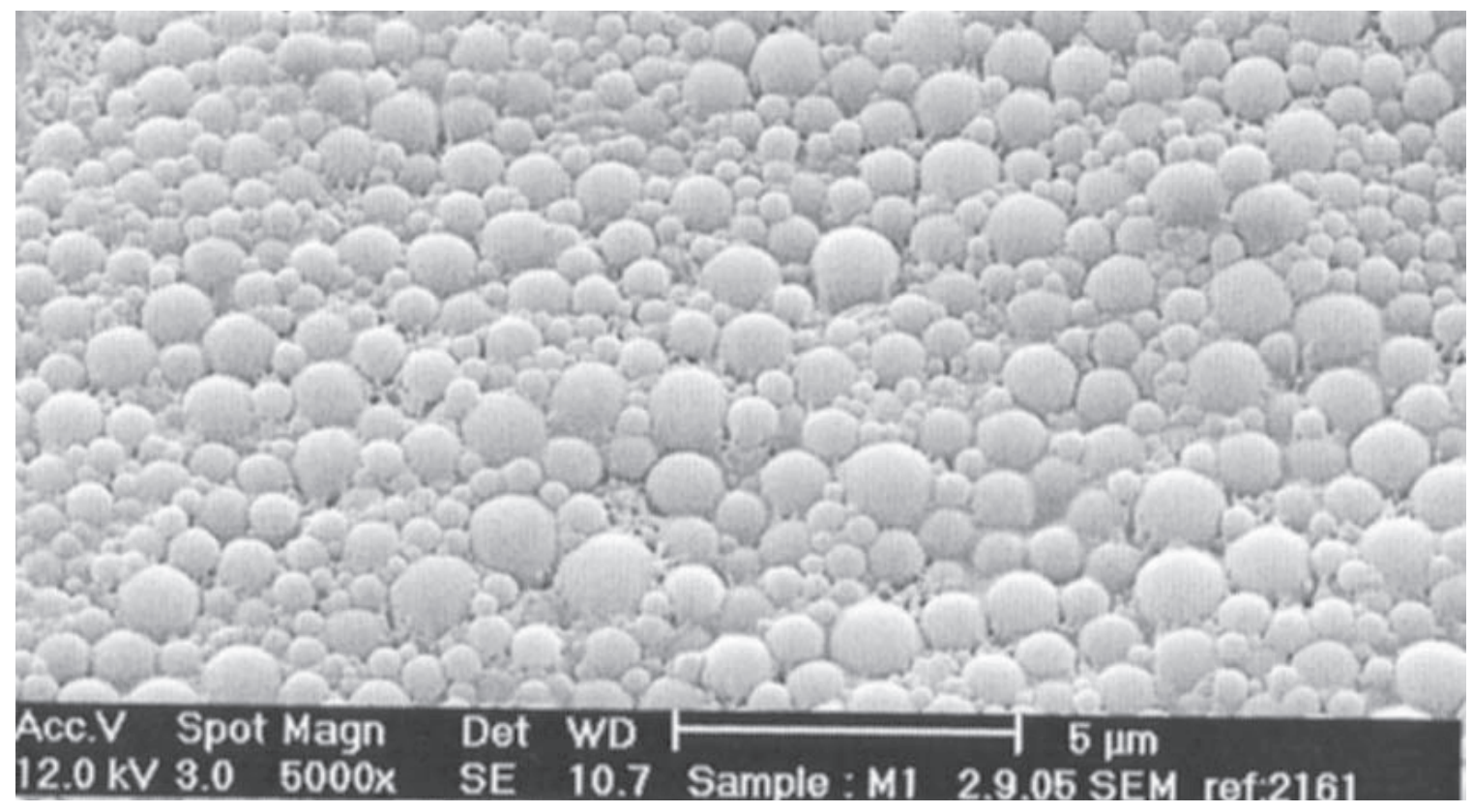

Figure 5 SEM photograph of the formulation G4.

product. PLGA coated with poloxamer (Pluronic F68) is also reported (Santander-Ortega et al 2006) for improved stability in colloidal state.

The SEM study (Figure 5) shows smooth and spherical shaped spheres in nano range. The average particle sizes of the formulations prepared at 10,000,12,500, 15,000, and 17,500 rpm are reported in Table 2. The data suggest that with increasing homogenizing speed average diameters of particles were reduced. However, when speed of homogenization was further enhanced, it was found interestingly that the average diameters of the particles were increased again. At 24,000 rpm, the average diameter became in micron range (approximately $2.869 \mu \mathrm{m}$ ). Higher energy due to higher homogenizing speed might have agglomerated nanospheres immediately after formation to provide larger spherical structures due to variable surface charges or any other similar cohesive forces generated due to the high energy process.

Protein loading is found to vary due to formulation compositions, methodology, process parameters etc. PLGA (50:50) was reported to have protein loading of 8-16\% (Lgartua et al 1998), which is about 2-4 times more ie, $\sim 38 \%$ in the experimental formulations prepared with PLGA (85:15), in the present study. Improved BSA loading was achieved in the prepared formulation G4 (38.6\%) in the present study. The protein-loading studies show that with increase in speed of homogenization, the loading capacity of formulation was increased. Likewise, the increase in amount of polymer also enhanced the loading of protein.
High homogenizing speed might vary the surface charges, which ultimately could load more protein (Basarkar et al 2007). The in-vitro protein release study was carried out for a period of 50 days. We studied a pretty long period for studying sustained release of protein. However, literature showed variable protein release study period from 35 days to 70 days (Zhu and Schwendeman 1999; Leach et al 2005).

Poly (lactide-co-glycolide) (PLGA), aliphatic polyester, has been well documented for its excellent biodegradability, biocompatibility and nontoxic properties (Loo et al 2004). PLGA varieties differ in their lactide-glycolide ratios which make PLGA varieties available in different molecular weights with variable physicochemical properties. The mechanical strength, swelling behavior, capacity to undergo hydrolysis, and subsequently the biodegradation rate are directly influenced with the lactide content of the PLGA polymer (Jain 2000). Present study was conducted with a more uncommon PLGA $(85: 15)$ than the commonly used PLGA (50:50) variety. Lactic acid is more hydrophobic than glycolic acid and hence lactide-rich PLGA (85:15) is less hydrophilic, absorbs less water, and subsequently degrade more slowly than PLGA (50:50) (Jain 2000). PLGA polymer containing lactic and glycolic acids in $85: 15$ ratio is hydrolyzed much slower than the PLGA (50:50) containing equal proportion of lacdide and glycolide. Molecular weight is indicative of chain length of polymers. By varying PLGA molecular weight, degradation of the 


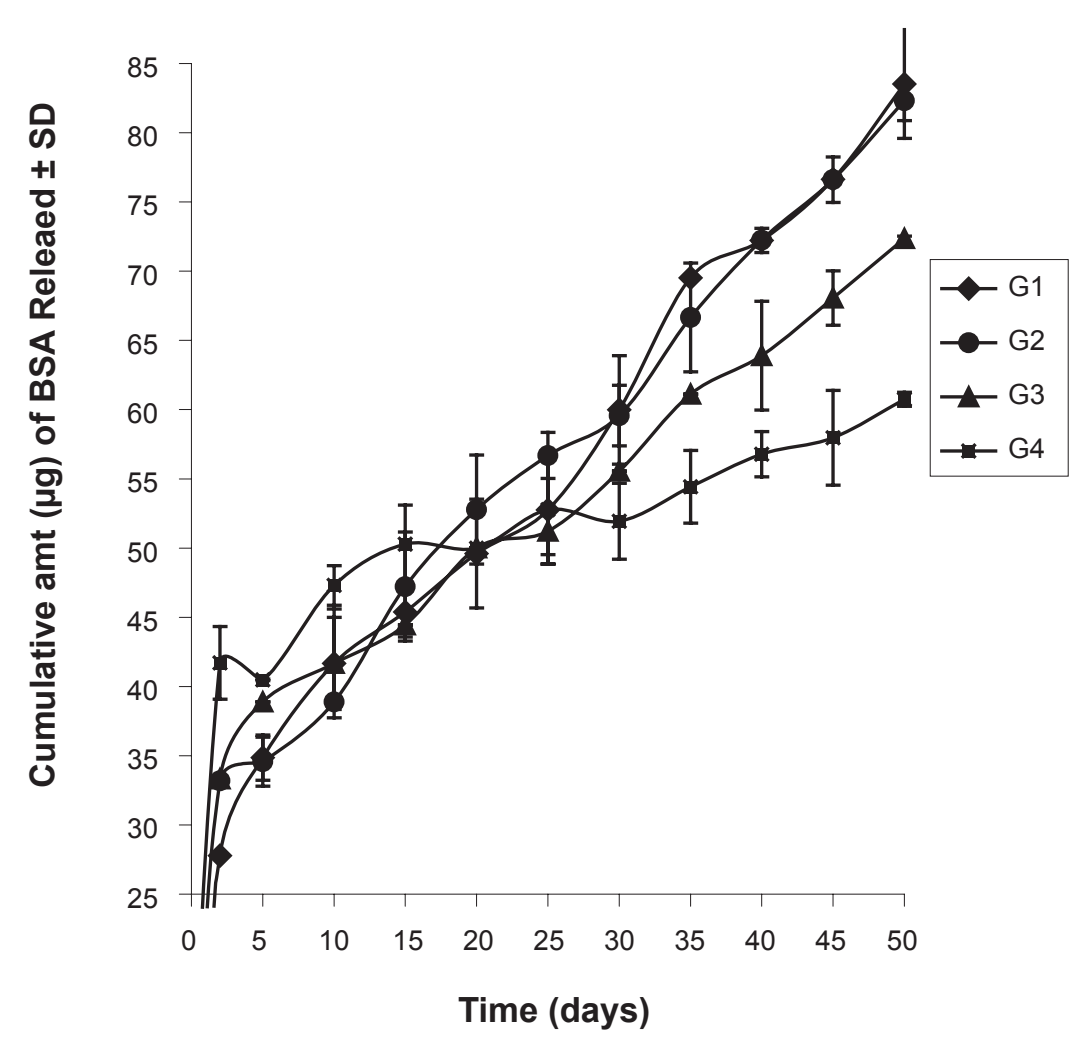

Figure 6 Cumulative amount of BSA released from the experimental formulations. Data shows mean $\pm S D(n=6)$.

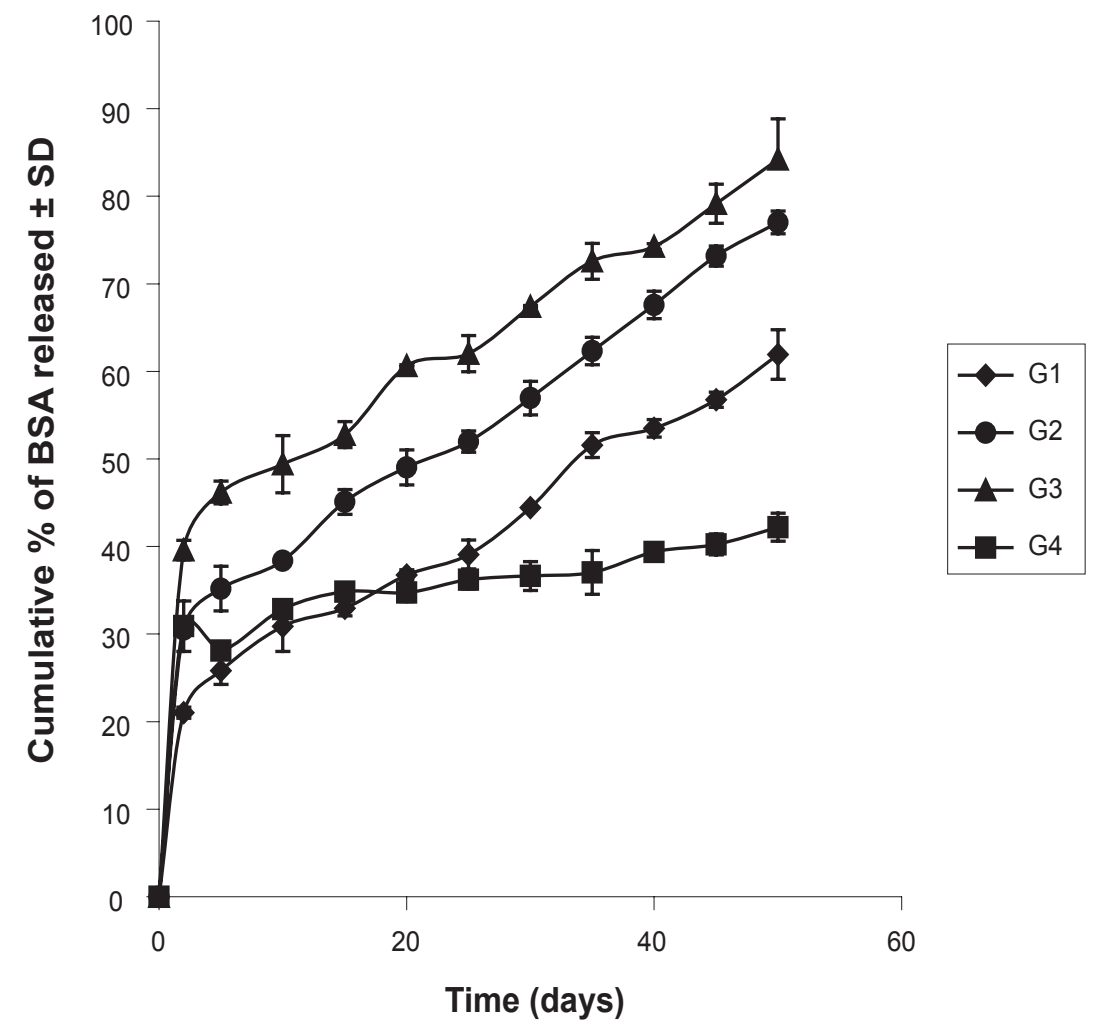

Figure 7 Cumulative percentage of BSA released from the experimental formulations. Data shows mean \pm SD $(n=6)$. 
Table 3 Release kinetics of BSA

\begin{tabular}{llll}
\hline Formulation code & Zero order & First order & Higuchi kinetics \\
\hline GI & $y=0.816 x+20.79 I$ & $y=-0.0063 x+1.9152$ & $y=7.0522 x+8.2225$ \\
& ${ }^{a} R^{2}=0.9902$ & $R^{2}=0.9801$ & $R^{2}=0.9597$ \\
G2 & $y=0.952 x+29.41$ & $y=-0.0096 x+1.8855$ & $y=8.2168 x+14.798$ \\
& $R^{2}=0.9967$ & $R^{2}=0.9705$ & $R^{2}=0.9635$ \\
G3 & $y=0.8795 x+40.416$ & $y=-0.0111 x+1.8204$ & $y=7.6683 x+26.553$ \\
& $R^{2}=0.9898$ & $R^{2}=0.97 \mid 4$ & $R^{2}=0.9764$ \\
G4 & $y=0.2429 x+29.625$ & $y=-0.0016 x+1.8485$ & $y=2.1136 x+25.817$ \\
& $R^{2}=0.923$ & $R^{2}=0.9312$ & $R^{2}=0.9066$
\end{tabular}

Note: ${ }^{\mathrm{a}}$ represents regression coefficient.

polymer and the release kinetics of BSA can be controlled. Higher molecular weight of PLGA (85:15) than PLGA (50:50) due to the presence of higher lactide chain lengths enhances the hydrophobicity and decreases the degradation of the polymers and rate of protein release. In the present study, the nanoparticles containing larger particles with the increased polydispersity indices showed slower release of BSA and it might be due to longer diffusion pathways of BSA in larger particles. However, more content of PLGA (85:15) showed the slowest BSA release in G4 among the formulations studied and it might be due to the enhancement of hydrophobicity. In the present study, the protein loading shows that increase in speed of homogenization increased the loading capacity of the formulation. Likewise, the increase in amount of polymer also enhanced the loading of protein. Increased entrapment efficiency was observed for particles of PLGA (85:15) with than PLGA (50:50), for their higher molecular weight and stronger hydrophobicity (Mittal et al 2007). Higher homogenizing speed might vary the surface charges of the polymers (Basarkar et al 2007), which ultimately could load more protein. In a study nanoparticles based on PLGA (85:15) without drug was showed to produce less polydispersity index than those with PLGA (50:50) (Mittal et al 2007). About 5\% statistically nonsignificant enhancement of nanoparticle sizes with PLGA (85:15) than PLGA (50:50) was reported in the literature (Mittal et al 2007). This indicates that increase lactide chain may not have great influence on particle size; rather the methodology has direct impact on the size reduction. In our study, variable homogenizing speed was found to be responsible for the size of nanoparticles and their polydispersity index.

Figure 6 and Figure 7 summarize the findings of in-vitro protein release study. Particles with smaller average diameter showed slower release. Smaller particles are generally formed with higher impact (Chen et al 2007). It varies the tortuous polymeric diffusion pathways in smaller particles (Zhang et al 2004). This ultimately leads to a sustained diffusion of protein from the particles. Formulations prepared with a BSA: PLGA ratio of 1:60 showed the slowest release pattern, among the formulations studied. Thus incorporation of extra amount of hydrophobic polymer, PLGA, might have caused more tortuous polymeric networks to deliver the protein for prolonged period of time maximally, among the experimental formulations.

The method provided a narrow-ranged densely-dispersed nanoparticles having capability of release of protein (BSA) more than 50 days. Thus, by regulating different process parameters and using a very simple method, BSA-loaded nanoparticles with a low polydispersity index can be produced and improved BSA loading and prolonged release profiles of BSA can be achieved.

\section{Conclusion}

PLGA polymer can be used to prepare nanoparticles containing BSA or similar proteins. Narrow-ranged densely-dispersed nanoparticles having a good protein- loading capacity and slow and sustained protein release characteristics could be developed using this simple technology. From the data provided, it is evident that nanoparticles prepared at $17,500 \mathrm{rpm}$ with a protein: polymer ratio of 1:60 satisfied the above criteria better than the other experimental formulations and hence it may be considered as the best among the prepared formulations, for further investigation.

\section{Acknowledgments}

The work was supported by University Grants Commission (Government of India); grant no. P-1/RS/404/07 and All India Council of Technical Education (Government of India), grant no.TEQIP/FD/ID/15/2005. A part of the work was 
carried out by Dr Biswajit Mukherjee in the Centre for Drug Delivery Research, The School of Pharmacy, University of London, UK.

\section{References}

Abdelwahed W, Degobert G, Stainmesse S, et al. 2006. Freeze-drying of nanoparticles: Formulation, process and storage considerations. Adv Drug Deliv Rev, 58:1688-713.

Banga AK, Chien YW. 1988. Systemic delivery of therapeutic peptides and proteins. Int J Pharm, 48:15-50.

Basarkar AA, Devineni DB, Palaniappan R, et al. 2007. Preparation, characterization, cytotoxicity and transfection efficiency of poly (dl-lactide-co-glycolide) and poly (dl-lactic acid) cationic nanoparticles for controlled delivery of plasmid DNA. Int J Pharm, 343:247-54.

Berkland C, Kim KK, Pack DW. 2001. Fabrication of PLG microspheres with precisely controlled and monodisperse size distributions. J Control Rel, 73:59-74.

Bilati U, Allémann E, Doelker E. 2005. Poly (D, L-lactide-co-glycolide) protein-loaded nanoparticles prepared by the double emulsion methodprocessing and formulation issues for enhanced entrapment efficiency. $J$ Microencapsule, 22:205-14.

Chen Y, Chen Y, Chen W, et al. 2007. Evolution of phase morphology of high impact polypropylene particles upon thermal treatment. Eur Poly $J, 43: 2999-3008$.

Chun W, Phuong-Truc P. 2008. Polymers for viral gene delivery. Expert Opin Drug Deliv, 5:385-401.

Cohen S, Yoshioka T, Lucarelli M, et al. 1991. Controlled delivery systems for protein based on poly (lactic/glycolic acid) microspheres. Pharm Res, 8:713-20.

Cunha-Filho MS, R. Martínez-Pacheco R, Landín M. 2007. Compatibility of the antitumoral beta-lapachone with different solid dosage forms excipients. J Pharm Biomed Anal, 45:590-8.

G'omez-Gaete C, Tsapis N, Besnard M, et al. 2007. Encapsulation of dexamethasone into biodegradable polymeric nanoparticles. Int J Pharm, 331:153-9.

Han SK, Lee JH, Kim D, et al. 2005. Hydrophilized poly (lactideco-glycolide) nanoparticles with core/shell structure for protein delivery. Sci Tech Adv Mat, 6:468-74.

Hermes RS, Narayani R. 2002. Polymeric alginate films and alginate beads for the controlled delivery of macromolecules. Trends Biomater Artif Organs, 15:54-6.

Jain R. 2000. The manufacturing techniques of various drug loaded biodegradable poly (lactide-co-glycolide) (PLGA) devices. Biomaterials, 21:2475-90.

Kavimandan NJ, Losi E, Peppas NA. 2006. Novel delivery system based on complexation hydrogels as delivery vehicles for insulin-transferrin conjugates. Biomaterials, 27:3846-54.

Kim JH, Taluja A, Knutson K, et al. 2005. Stability of bovine serum albumin complexed with PEG-poly (1-histidine) diblock copolymer in PLGA microspheres. J Control Rel, 109:86-100.

Lamprecht A, Ubrich N, Hombreiro Pérez M, et al. 1999. Biodegradable monodispersed nanoparticles prepared by pressure homogenizationemulsification. Int J Pharm, 184:97-105.

Leach WT, Simpson DT, Val TN, et al. 2005. Encapsulation of protein nanoparticles into uniform-sized microspheres formed in a spinning oil film. AAPS PharmSciTech, 6:75.

Lee SH, Zhang Z, Si-Shen F. 2007. Nanoparticles of poly (lactide)-tocopheryl polyethylene glycol succinate (PLA-TPGS) copolymers for protein drug delivery. Biomaterials, 28:2041-50.
Lgartua M, Hernández RM, Esquisabel A, et al. 1998. Stability of BSA encapsulated into PLGA microspheres using PAGE and capillary electrophoresis. Int J Pharm, 169:45-54.

Loo S, Ooi C, Boey Y. 2004. Influence of electron-beam radiation on the hydrolytic degradation behaviour of poly (lactide-co-glycolide) (PLGA). Biomaterials, 26:3809-17.

Maghraby AM, Ali MA. 2007. Spectroscopic study of gamma irradiated bovine hemoglobin. Rad Phys Chem, 76:1600-5.

Mittal G, Sahana DK, Bhardwaj V, et al. 2007. Estradiol loaded PLGA nanoparticles for oral administration: Effect of polymer molecular weight and copolymer composition on release behavior in vitro and in vivo. J Control Rel, 119:77-85.

Mohanraj VJ, Chen Y. 2006. Nanoparticles - A Review. Trop J Pharm Res, 5:567-73.

Mukherjee B, Kanupriya, Mahapatra S, et al. 2005b. Sorbitan monolaurate 20 as a potential skin permeation enhancer in transdermal patches. $J$ Appl Res, 5:96-108.

Mukherjee B, Mahapatra S, Gupta R, et al. 2005a. A comparison between povidone-ethylcellulose and povidone-eudragit transdermal dexamethasone matrix patches based on in vitro skin permeation. Eur J Pharm Biopharm, 59:475-8.

Muller RH, Keck CM. 2004. Challenges and solutions for the delivery of biotech drugs - a review of drug nanocrystal technology and lipid nanoparticles. $J$ Biotech, 113:151-70.

Panyam J, Dali MM, Sahoo SK, et al. 2003. Polymer degradation and in vitro release of a model protein from poly (D, L-lactide-co-glycolide) nano- and microparticles. $J$ Control Rel, 92:173-87.

Panyam J, Labhasetwar V. 2003. Biodegradable nanoparticles for drug and gene delivery to cells and tissue. Adv Drug Deliv Rev, 55:329-47.

Qaddoumi MG, Ueda H, Yang J, et al. 2004. The characteristics and mechanisms of uptake of PLGA nanoparticles in rabbit conjunctivital epithelial cell layers. Pharm Res, 21:641-8.

Ravi Kumar MNV. 2000. Nano and microparticles as controlled drug delivery devices. J Pharm Pharmaceut Sci, 3:234-58.

Santander-Ortega MJ, Jódar-Reyes AB, Csaba N, et al. 2006. Colloidal stability of Pluronic F68-coated PLGA nanoparticles: A variety of stabilisation mechanisms. J Colloid Interface Sci, 302:522-9.

Senthilkumar M, Mishra P, Jain NK. 2008. Long circulating PEGylated poly (D, L-lactide-co-glycolide) nanoparticulate delivery of Docetaxel to solid tumors. J Drug Target, 16:424-35.

Shoyele SA, Slowey A. 2006. Prospects of formulating proteins/peptides as aerosols for pulmonary drug delivery. Int J Pharm, 314:1-8.

Song CX, Labhasetwar V, Murphy H, et al. 1997. Formulation and characterization of biodegradable nanoparticles for intravascular local drug delivery. J Control Rel, 43:197-212.

Wei-Chiang S. 2003. Oral peptide and protein delivery: unfulfilled promises. Drug Discov Today, 8:607-8.

Ya-Ping L, Yuan-Ying P, Xian-Ying Z, et al. 2001. PEGylated PLGA nanoparticles as protein carriers: synthesis, preparation and biodistribution in rats. J Control Rel, 71:203-11.

Yue PF, Yuan HL, Yang M, et al. 2008. Preparation, characterization, and pharmacokinetic evaluation of puerarin submicron emulsion. PDA J Pharm Sci Technol, 62:32-45.

Zhang K, Wang Y, Hillmyer MA, et al. 2004. Processing and properties of porous poly (L-lactide)/bioactive glass composites. Biomaterials, 25:2489-500.

Zhu G, Schwendeman SP. 1999. Stability and controlled release of proteins encapsulated in poly (lactide-co-glycolide) microspheres [online]. Accessed on August 20, 2008. URL: http://www.aapspharmsci.org/ abstracts/AM_1999/2511.htm. 